\title{
Influence of the Shape of Back on the Thoraco-lumbar Fractures
}

\author{
Mourad Aoui ${ }^{1}$, Moez Trigui ${ }^{1 *}$, Abdessalem Naceur ${ }^{1}$, Ameur Abid ${ }^{1}$, Nader Trigui ${ }^{1}$, Sami Maghrebi ${ }^{2}$ and Hassib Keskes ${ }^{1}$ \\ ${ }^{1}$ Department of Orthopedics and Traumatology, Habib Bourguiba University Hospital, Faculty of Medicine, Sfax, Tunisia \\ ${ }^{2}$ Department of Anesthesiology and Intensive Care, Habib Bourguiba University Hospital, Sfax Faculty of Medicine, Sfax, Tunisia
}

\begin{abstract}
Introduction: The surgical management of degenerative and malformative spinal deformities takes into account the pelvic and spinal parameters. This concept is not applied in traumatology.
\end{abstract}

Purpose: To adapt the correction of traumatic kyphosis deformity to the type of backs in function of pelvic incidence and to study the influence of the shape of backs on the localization, the type of fracture, the correction, and the loss at follow-up.

Methods: It is a prospective study of 80 patients operated from February 2005 to December 2010. Mean folloupup was 52 months (18-72). Patients were treated by the same surgeon by a posterior osteosynthesis using in situ contouring technique. We evaluated kyphosis deformity according the shape of backs assessed by the value of the pelvic incidence $(\mathrm{Pl})$ calculated in lying position.

Results: Our patients were classified with low PI (type 1,2) in 35\% of cases and high PI (type 3, 4) in 57\% of cases. No significant difference was found in the repartition of fracture levels, type of fracture and the kyphosis deformity. However, the number of patients with good correction and with loss at follow-up was important in high pelvic incidence $(p<0.001)$

Discussion: Neurologic status is not the only point of decision in chirurgical treatment. The kyphosis deformity in trauma is also an important point, but this angle is not always easy to measure. The relationship between deformities with injury level of spine depends on type of backs. A patient with trauma (lying position), pelvic incidence is the only angle which gives an idea about the shape of backs. According to Roussouly's classification, type 1 (long thoracolumbar kyphosis) and type 2 (flat), the correlation at the injury level is not necessary, but for type 3 and 4 (with harmony curvature), the correlation seems logical.

Keywords: Thoraco-lumbar fracture; Pelvic incidence; Shape of back; In situ contouring technique.

\section{Introduction}

Thoraco-lumbar fractures are the most frequent spinal injuries [13]. The traumatic injury first leads to a kyphotic deformity [4] noted and measured as previously described by several authors [5-8]. In fact, young and active people are the most affected by those fractures [9]. Actually, because of the constraint sand disappointment due to the orthopedic treatment [10], these fractures are more surgically treated. To treat fractures, it needs to take into account the requirements of modern life: short hospitalization, refusal to wear plasters or brace, and early return to social and even to professional duties. Each surgical technique differs according to its type of anchorage (screw or hooks), its linking elements (rod or plate) and the vertebral levels instrumented above and below the fracture. So to reduce the traumatic deformity, internal or external maneuvers are essential. This is the objective of the treatment before fixing the spine in the adequate position, but the kyphosis angle is not always easy to measure [11]. For some authors, the value of this deformity must be correlated with the injury level of spine, others do not index their measurements at the affected level $[5,7,12$ 16]. Our objective was to prove the relationship between shape of back (pelvic incidence) (PI) and parameters, which evaluate the kyphosis deformity in thoraco-lumbar trauma. Pelvic parameters defined for many years by Duval-Beaupère and legaye $[17,18]$ are significant chain of correlations between positional pelvic and spinal parameters which are fundamental for the surgical management of spinal degenerative and malformative deformities [19-21]. Although, this concept is less spread in thoraco-lumbar fractures. With injured patients, PI is the only pelvic angle which helps us to understand the sagittal balance spine and gives an idea about the shape of back and about the degree of the kyphosis deformity.
The Purpose of this study was to adapt the correction of traumatic kyphosis deformity to the type of backs in function of PI and to study the influence of the shape of backs on the localization, the type of fracture, the correction, and the loss at follow-up.

We conducted a prospective and observative study of 80 thoracolumbar fractures, operated on by the same surgeon. Reduction was performed by the in situ contouring technique described by Jackson [22] and Steib [2].

\section{Patients and Methods}

The study was composed of 80 injured patients, mean age 36 years (16-68.), BMI 25.39 (19-31) with a majority of men (61 men versus 19 women). The type of trauma was variable but home accidents were mostly encountered (Table 1). These fractures were treated by the same team from february 2005 to December 2010. Mean follow up was 52 months (18-72). The thoraco-lumbar junction fractures were defined as T12-L1 fractures, with extension to T11 and L2 (Table 1) [1,23] The most frequent fractured level was L1. Fractures were classified according to Denis [24], as this classification seems to us the easiest to use (Table 1). We recorded a majority of Burst fractures (62\%). The

*Corresponding author: Moez Trigui, Department of Orthopedics and Traumatology, Habib Bourguiba University Hospital, Faculty of Medicine, Sfax, Tunisia, Tel: 74241511; E-mail: dr moez trigui@yahoo.fr

Received December 31, 2014; Accepted January 23, 2015; Published January 25, 2015

Citation: AAoui M, Trigui M, Naceur A, Abid A, Trigui N, et al. (2015) Influence of the Shape of Back on the Thoraco-lumbar Fractures. J Spine 4: 209 doi:10.4172/21657939.1000209

Copyright: (C) 2015 Aoui M, et al. This is an open-access article distributed under the terms of the Creative Commons Attribution License, which permits unrestricted use, distribution, and reproduction in any medium, provided the original author and source are credited. 


\begin{tabular}{|c|c|c|c|}
\hline & & Number & Percentage \\
\hline Gender & $\begin{array}{c}\text { Male } \\
\text { Female }\end{array}$ & $\begin{array}{l}61 \\
19\end{array}$ & $\begin{array}{l}76.3 \% \\
23.8 \%\end{array}$ \\
\hline Antecedents & $\begin{array}{l}\text { None } \\
\text { Diabetes } \\
\text { Surgery } \\
\text { Spinal } \\
\text { Other }\end{array}$ & $\begin{array}{c}63 \\
2 \\
2 \\
3 \\
10\end{array}$ & $\begin{array}{c}78.8 \% \\
2.5 \% \\
2.5 \% \\
3.8 \% \\
12.5 \%\end{array}$ \\
\hline Etiology & $\begin{array}{c}\text { Road accidents } \\
\text { Work accident } \\
\text { Home accidents } \\
\text { Other }\end{array}$ & $\begin{array}{c}14 \\
33 \\
24 \\
9\end{array}$ & $\begin{array}{l}17.5 \% \\
41.3 \% \\
30.0 \% \\
11.3 \%\end{array}$ \\
\hline Associated injuries & $\begin{array}{c}\text { None } \\
\text { Cerebral } \\
\text { Thoracic } \\
\text { Abdominal } \\
\text { Limbs } \\
\text { Cervical }\end{array}$ & $\begin{array}{c}47 \\
3 \\
8 \\
1 \\
19 \\
2\end{array}$ & $\begin{array}{c}58.8 \% \\
3.8 \% \\
10.0 \% \\
1.3 \% \\
23.8 \% \\
2.5 \%\end{array}$ \\
\hline Neurological status & $\begin{array}{l}\text { Undamaged } \\
\text { Frankel A } \\
\text { Frankel B C D } \\
\text { Cauda equina } \\
\text { syndrome }\end{array}$ & $\begin{array}{c}54 \\
10 \\
14 \\
2\end{array}$ & $\begin{array}{c}67.5 \% \\
12.5 \% \\
17.5 \% \\
2.5 \%\end{array}$ \\
\hline Level of injury & $\begin{array}{l}\text { T10 } \\
\text { T12 } \\
\text { L4 } \\
\text { L1 } \\
\text { L2 } \\
\text { L3 }\end{array}$ & $\begin{array}{c}3 \\
12 \\
15 \\
25 \\
13 \\
12\end{array}$ & $\begin{array}{c}3.8 \% \\
15.0 \% \\
18.8 \% \\
31.3 \% \\
16.3 \% \\
15.0 \%\end{array}$ \\
\hline Denis classification & $\begin{array}{l}\text { Burst } \\
\text { Seat-belt } \\
\text { Dislocation }\end{array}$ & $\begin{array}{l}50 \\
18 \\
12\end{array}$ & $\begin{array}{l}62.5 \% \\
22.5 \% \\
15.0 \%\end{array}$ \\
\hline
\end{tabular}

Table 1 : Study caracterestics

majority of the injured experienced with no neurological troubles $(68 \%$ Frankel E). There were 9 complete paraplegias (Frankel A) and 17 incomplete neurological troubles (3 frankel B, 5 Frankel C, 9 Frankel D) (Table 1). In order to analyze the deformity, we studied the relation between the traumatic vertebra and the adjacent vertebrae (Figure 1) [1] on preoperative X-rays (lying position) as well as on immediate and long term post-operative X-rays (upright full spine X-rays). We were more interested not only with the relative deformation but also with the real deformation. Farcy sagittal index (SIF) [25] brings the real notion of the importance of the traumatic kyphosis [1]. It corresponds to the segmental kyphosis (SK) [one disc, one vertebra (inferior endplate of the injured vertebra/inferior endplate of the overlying vertebra)] diminished by the segment physiological kyphosis, which arbitrarily amounts to $5^{\circ}$ in the thoracic spine, $-10^{\circ}$ in the lumbar spine and $0^{\circ}$ in T12-L1. The normal index is zero. According to Roussouly's classification of lumber lordosis into four types to define the shape of the spine (type 1 and 2 with low IP $<50^{\circ}$; type 3 and 4 with high: IP $\geq$ $50^{\circ}$ ) [26]. The SIF is not valuable for type 1 with long thoracolumbar kyphosis and short lordosis. The same for type 2 with flat lordosis. The Gardner segment kyphotic deformity (GSKD): angle defined by the tangent to the upper endplate of the vertebra overlying the injured vertebra and the tangent to the lower endplate of the injured vertebra (Two vertebrae, one disc). This parameter is valuable for all backs (independent curvatures: low or high PI) [14]. The statistical analysis, the Student-t and Mann-Whitney-tests, $\mathrm{Chi}^{2}$ test were used to estimate the significance of the results, by means of the SPSS statistics 17.0.

In case of neurological complications, patients underwent emergency operation. If not, they were treated some time after. The surgical treatment always consisted of a posterior osteosynthesis. A laminoarthrectomy was performed only in case of neurological signs. Canal stenosis did not constitute a release criterion. The construct was identical in 51 cases and hybrid in 29 cases: bilateral and symmetrical with screws protected by hooks as Argenson precised from 1987 onwards $[27,28]$. Such construct diminishes the mobility of pedicular screws [28] and protects them from excessive stress. The standard construct consisted in pedicular screws inserted in tow vertebrae overlying the fracture. At the bottom, screws were protected by offset hooks inserted on the same vertebra. Opening the canal is not necessary (blade of the sublaminar hook positioned between the bone and the ligamentum flavum). The rod is contoured below to be positioned far from the spine. After closing the high segment, the rod is inserted down the body of lower implants by in situ contouring. This maneuver is meant to give the rod the shape of the spine and then to give the spine the shape of the rod freely. Reduction is performed by bilateral and symmetrical actions (both rods at the same time) using bending irons. These instruments are inserted between the screws. The surgeon and his assistant transmit a movement to bring the bending irons closer. This maneuver gives a lordosis shape to the rod. Bending irons are then positioned at either side of the upper screws and the same maneuver is performed. The first movement opens the fracture site; the second movement opens the overlying disc which is often the most compromised. This step may need to be repeated until satisfying reduction is achieved. The correction obtained can be estimated by radioscopy or by positioning the screwdriver into the screws, to obtain the regional lordosis. There is no elongation stress on the spine, just a correction of the lordosis. Before locking the implants, the frontal balance of the construct must be improved (implants on the same vertebra forming a perpendicular line with the rod) by compressiondistraction maneuvers [1,2]. The sub-laminar hook is locked in compression on the screw that it protects. The postero-lateral articular graft is then implanted. Patients rapidly got up without any external fixation (4 days) $[1,12,29]$. Radiologic measurements are made by three different surgeons. The clinical results were evaluated according to Oswestry score [30].

\section{Results}

Osteosynthesis was considered as long when we fix two discs below and above the fracture (64\%) and as hybride for the others: every time we fix two discs above and one disc below (36\%). Osteosynthesis was always protected by posterior and postero-lateral graft. The operation was done within 12 days (1-21). Non-neurological patients waked-up at the fourth day (2-7) without any external contention. Hospitalization lasted 4 days (5-30).

Post traumatic deformity from $17.35^{\circ}$ for the SIF arrived at $-1.2^{\circ}$ (correction $18.55^{\circ}$ ), for GSKD from $19^{\circ}$ can reach $-0.58^{\circ}$ (correction $19.58^{\circ}$ ). The vertebral kyphosis (VK) passed from $17.6^{\circ}$ to $3.99^{\circ}$ (correction $13.7^{\circ}$ ). In the last follow-up, the loss of correction was $\left(\mathrm{VK}=0.27^{\circ}, \mathrm{SIF}=2.4^{\circ}, \mathrm{GSKD}=2.49^{\circ}, \mathrm{P}<0.0001\right)$. The real gain was $\left(\mathrm{VK}=12.8^{\circ}, \mathrm{SIF}=2.04, \mathrm{GSKD}=2.49^{\circ}\right)($ Table 2$)$.

The estimation of deformity for the two parameters (SIF, GSKD) did not have a significant difference for the whole study, this was explained by the important number of fractures in T12-L1 level (37 patients) (Figure 2) that corresponds to a flat segment. On the contrary, the value of these parameters was not the same according to the zone touched $(p<0.0001)($ Table 3$)$. This is given us an idea to add a new parameter: pelvic incidence, the only angle calculated in patients with trauma, which divided our patients into two groups [29]: with low incidence $\left(<50^{\circ}\right)$ (29 patients) and with high incidence $(\geq 50)(51$ patients). Angular measurements in these two groups appear in the Table 4. We noticed that there was not a significant statistic difference between these two groups in level, type and neurological status (Table 5).

According to the correction obtained, a normal correction had a 
Citation: Aoui M, Trigui M, Naceur A, Abid A, Trigui N, et al. (2015) Influence of the Shape of Back on the Thoraco-lumbar Fractures. J Spine 4: 209. doi:10.4172/21657939.1000209

Page 3 of 6

\begin{tabular}{|c|c|c|c|c|c|c|c|}
\hline Item & $\begin{array}{l}\text { Preoperative } \\
\qquad(n=80)\end{array}$ & $\begin{array}{l}\text { Postoperative } \\
\qquad(n=80)\end{array}$ & $\begin{array}{l}\text { Correction } \\
\qquad(n=80)\end{array}$ & $\begin{array}{l}\text { Follow-up } \\
\qquad(n=80)\end{array}$ & $\begin{array}{l}\text { Real gain } \\
\qquad(n=80)\end{array}$ & $\begin{array}{l}\text { Loss } \\
(n=80)\end{array}$ & $\begin{array}{c}\mathrm{P} \text { (Test T de } \\
\text { Student) }\end{array}$ \\
\hline VK & $17.06^{\circ}$ & $3.99^{\circ}$ & $13.07^{\circ}$ & $4.26^{\circ}$ & $12.8^{\circ}$ & $0.27^{\circ}$ & $p<0.001$ \\
\hline SIF & $17.35^{\circ}$ & $-1.20^{\circ}$ & $18.55^{\circ}$ & $0.84^{\circ}$ & $16.51^{\circ}$ & $2.04^{\circ}$ & $p<0.001$ \\
\hline GSKD & $19.00^{\circ}$ & $-0.58^{\circ}$ & $19.58^{\circ}$ & $1.91^{\circ}$ & $17.08^{\circ}$ & $2.49^{\circ}$ & $p<0.001$ \\
\hline
\end{tabular}

Table 2: Radiological parameters of study

Local kyphosi (LK)s=vertebral kyphosis: angle defined by the tangent to the upper endplate and the lower endplate of the injured vertebra

Segmental kyphosis (SK): angle defines by the tangent to the lower endplate of the injured vertebra and the tangent to the lower endplate of the vertebra overlying the injured vertebra.

One vertebra, one disc=one segment

Sagittal index (Farcy): SI=SK-X(X=+5 in the thoracic spine,

$X=-10$ in the lumbar spine, $X=0$ in $T 12-L 1$ )

Gardner segment kyphotic deformity (GSKD): angle defined by

the tangent to the upper endplate of the vertebra overlying

the injured vertebra and the tangent to the lower endplate

of the injured vertebra. Two vertebrae, one disc. Interesting

when the upper endplate of the injured vertebra is no

Fig. 1 : Angular measurements

more identifiable

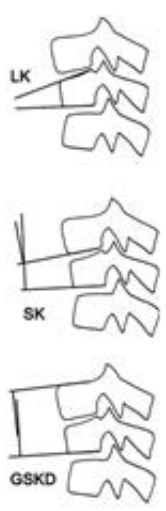

Figure 1: Angular measurements

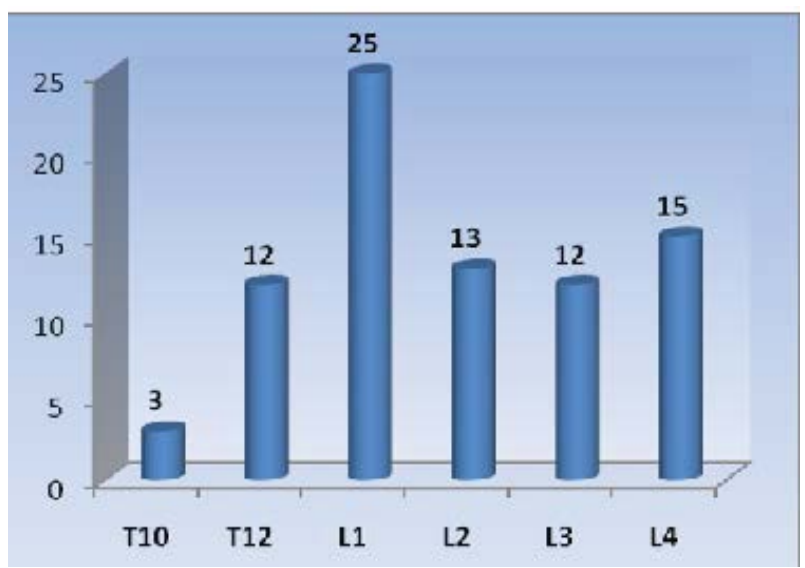

Figure 2: Distribution of patients by vertebral level.

SIF $=0^{\circ},+10^{\circ},-1^{\circ}$ in back with IP $\geq 50^{\circ}$, and a GSKD $=0^{\circ},+1^{\circ},-1^{\circ}$ in back with $\mathrm{IP}<50^{\circ}$. The hyper correction had a SIF $<-1^{\circ}$ or GSKD $<-1^{\circ}$ and the hypo correction with (SIF $>+1^{\circ}$ or GSKD $>+1^{\circ}$ ) (Table 6).

The correction was acceptable (normal or hyper correction) in 69\% of cases for patients with a high pelvic incidence, $31 \%$ of patients with a low pelvic incidence $(\mathrm{p}<0.001)$.

The clinical results were good with an Oswestry score amounting to 32 (10-70). There was no correlation between the shape of spine (low and high incidence) and the clinical score. Thirty nine patients were able to go back to their previous work 9 months after surgery on average (6-36 months), 11 were not able to do so and 30 were unemployed.

We observed 2 phlebitis and 2 superficial infections. Complications of the posterior approach were 5 dural breaches sutured without any sequela, 2 cases dismounting and a non-union, both of which have been reoperated on with a new posterior construct. In this emergency surgery, there were eight sepsis cases (10\%). However, none dismantling and none required material removal.
The sagittal balance evaluated by an entire X-ray of spine, took three or six months after surgery (53 patients without neurologic deficit) allows us to verify the type of back finding an error in two patients (3\%). The unbalance is found in 6 patients $(11 \%)$.

\section{Discussion}

To compare with literature, our functional results are good $[9,16,31]$, they are better than the results obtained by orthopedic treatment $[31,32]$. Before non-chirurgical treatment is practiced in $80 \%$ of fractures without neurological complications [33]. The neurological status is not the only point of decision in chirurgical treatment. The deformity in sagittal plan is also an important point [2].

The criteria of selection are extremely variables [8,32-34], the majority are an angulation $>25^{\circ}$ or a compression $>50^{\circ}[1]$.

The post traumatic kyphosis is a true complication of spinal fracture and it is most frequent at the thoraco-lumbar junction [34], leading to back pain and neurological sequela. The kyphosis angle even it is not always easy to measure [11].

For some authors, the value of this deformity must be correlated with the injury level of spine and a slight kyphosis is acceptable in T11-T12 unaccepable in L1-L2 which is normally a level in lordosis while a flat area is wanted in T12-L1 [1,2]. If the local kyphosis (LK) angle gives an idea about the importance of the traumatism but the regional kyphosis (RK) is meaningless if it is not correlated to the level. Farcy [25] was one of the first to make this distinction by defining the sagittal index Farcy (SIF) after Stagnara's study [35]. He admitted a $5^{\circ}$ kyphosis at each thoracic level, a $10^{\circ}$ lordosis at each lumbar level and $0^{\circ}$ in T12-L1 .The SIF corresponds to the difference between the calculated angulation and the ideal angulation.

Most authors do not index their measurement at the affected level [5,7,12-16]. Among them, Korovessis [14] used the Gardner Segment Kyphosis Deformity (GSKD) wich is interesting when the upper endplate of the injured vertebra is no more identifiable.

In our study, we are based on pelvic incidence defined for many years by Duval-Beaupère and Legaye [17] calculated on profile radiography of lumbosacral junction taken both femoral heads. It is a proper angle for every primordial individual to understand the thoraco-lumbar sagittal balance, but it cannot be modified as the growth is achieved. The value of this incidence gives us an idea about the type of backs in order to adapt the adequate parameter. Backs with low incidence $<50^{\circ}$ are classified according to Roussouly in type 1(with high thora-columbar kyphosis and a little lordosis), type 2 (with plate back) [26]. For these types of backs, we have rejoined the authors who used the parameter independently for injury level such as the GSKD (Figure 3). On the contrary, backs with high incidence classified in type 3 and 4 with harmony curvature [26], the correlation between the regional kyphosis and the level injury gives the real deformity. The SIF is applicable for these backs (Figure 4).

Our hypothesis for the influence of the shape of back on thoraco- 
Citation: Aoui M, Trigui M, Naceur A, Abid A, Trigui N, et al. (2015) Influence of the Shape of Back on the Thoraco-lumbar Fractures. J Spine 4: 209. doi:10.4172/21657939.1000209
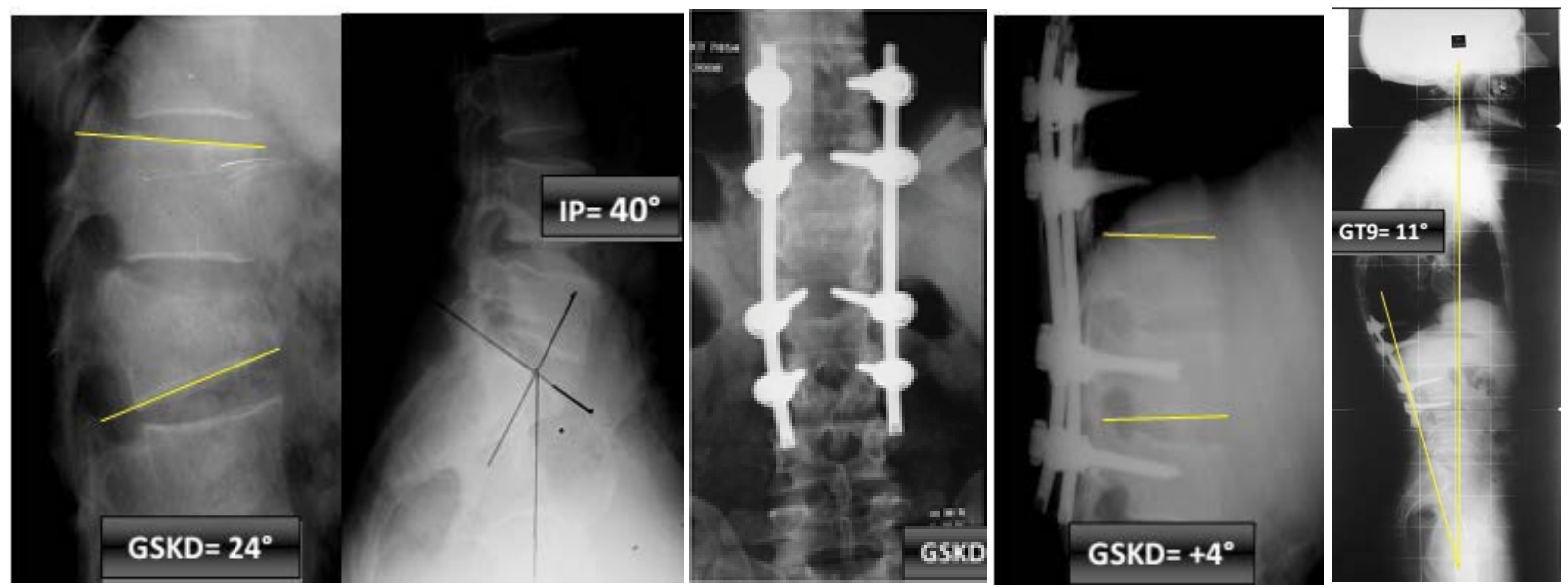

Figure 3: Case 1: L1 burst fracture, without neurologic signs, GSKD $=24^{\circ}, \mathrm{PI}=40^{\circ}$, Real Gain $=20^{\circ}$ without loss at follow-up
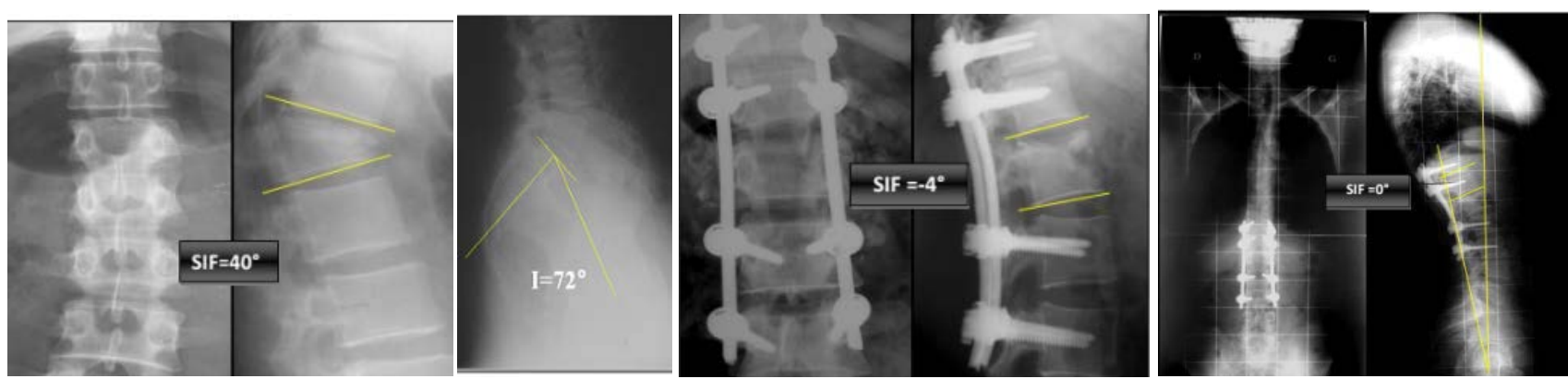

Figure 4: Case 2: L1 burst Fracture, without neurologic signs, $\mathrm{SIF}=40^{\circ}, \mathrm{PI}=72^{\circ}$, Real Gain $=40^{\circ}$, follow-up of 4 years, good balance, with little loss of correction

lumbar fractures consists in choice the parameters which evaluate the traumatic deformity in function of pelvic incidence the only parameter calculated in injured patients.

The results of our study confirm our hypothesis by the significant difference of the traumatic deformity value found by the calculation of the SIF and the GSKD in the different segments of back (Table 3). This difference is not significant for the whole study seeing the important number of fractures in $\mathrm{T} 12-\mathrm{L} 1(46 \%)$ in which the deformity is not major which make the values of SIF and GSKD near of each other $\left(17.35^{\circ}, 19^{\circ}\right)$ (Table 2). The type of back is not influenced by the gender, age and BMI. The thoraco-lumbar junction is the most touched in our study $(63 \%)$ similar to literature $[1,2,34]$. This notion is found in backs with high pelvic incidence (64\%), but for backs with low pelvic incidence, this notion is less important (53\%) without statistically significant difference.

The global correction is satisfied for the whole study, with real gain $12,8^{\circ}(\mathrm{VK}), 16,51^{\circ}$ (SIF), $17,08^{\circ}$ (GSKG) compared to literature $[1,25]$. The number of patients well-corrected by this technique varies in function of type of back (Table 5). Also, for backs with high incidence a good correction is obtained in $69 \%$ of cases whereas $31 \%$ for backs with low incidence $(\mathrm{p}<0.001)$.

The loss in follow up are minims, $0,27^{\circ}$ (VK), 2,04 ${ }^{\circ}$ (SIF) and $2,49^{\circ}$ (GSKD) compared in study of literature [1] (Table 2). This loss is proportional to pelvic incidence: more important in patients with high pelvic incidence $(\mathrm{p}<0.002)$ (Table 4$)$. The discordance between the good functional results and the radiologic results in patients with low pelvic incidence (hypo correction $=69 \%$ ) (Table 6 ), proves the kyphotic

\begin{tabular}{|c|c|c|c|c|}
\hline & Vertebral Level & & \\
\hline Th & Thoracic $n=3$ & $\begin{array}{c}\text { thoracolumbar } \\
\text { junction } n=50\end{array}$ & Lumbar $n=27$ & $\begin{array}{c}\mathrm{P} \text { (Student } \\
\text { test) }\end{array}$ \\
\hline GSKD & $15,3^{\circ}$ & $20,4^{\circ}$ & $\mathbf{1 0 , 2}^{\circ}$ & $(\mathrm{P}<0,001)$ \\
\hline SIF & $18^{\circ}$ & $23,8^{\circ}$ & $\mathbf{9}^{\circ}$ & $(\mathrm{P}<0,001)$ \\
\hline
\end{tabular}

Table 3: Angular deformity according to the vertebral Zone

\begin{tabular}{|c|c|c|c|c|}
\hline & \multirow[b]{2}{*}{ Item } & \multicolumn{2}{|c|}{ Pelvic incidence } & \multirow[b]{2}{*}{ P (Student Test) } \\
\hline & & $\begin{array}{c}\text { Low }<50^{\circ} \\
\mathrm{N}=29\end{array}$ & $\begin{array}{c}\text { High } \geq 50^{\circ} \\
N=51\end{array}$ & \\
\hline Deformation & $\begin{array}{c}\text { VK } \\
\text { SIF } \\
\text { GSKD }\end{array}$ & $\begin{array}{l}19,17^{\circ} \\
17,93^{\circ} \\
22,07^{\circ}\end{array}$ & $\begin{array}{l}15,86^{\circ} \\
17,02^{\circ} \\
17,25^{\circ}\end{array}$ & $\begin{array}{l}0,124 \\
0,716 \\
0,091\end{array}$ \\
\hline Correction & $\begin{array}{c}\text { VK } \\
\text { SIF } \\
\text { GSKD }\end{array}$ & $\begin{array}{l}13,68^{\circ} \\
15,89^{\circ} \\
18,48^{\circ}\end{array}$ & $\begin{array}{l}12,72^{\circ} \\
20,05^{\circ} \\
20,19^{\circ}\end{array}$ & $\begin{array}{l}0,651 \\
0,117 \\
0,501\end{array}$ \\
\hline Loss & $\begin{array}{c}\text { VK } \\
\text { SIF } \\
\text { GSKD }\end{array}$ & $\begin{array}{l}0.51^{\circ} \\
2.03^{\circ} \\
1.48^{\circ}\end{array}$ & $\begin{array}{l}0.56^{\circ} \\
2.82^{\circ} \\
3.45^{\circ}\end{array}$ & $\begin{array}{l}0.877 \\
0.258 \\
0.002\end{array}$ \\
\hline
\end{tabular}

Table 4: Correlation between pelvic incidence and vertebral deformity, gain and loss of correction

attitude of these backs with low incidence [26].

The limitation of our study is that the different radiologic parameters were measured manually. These measures would be more precise if we used adapted software.

\section{Conclusion}

The treatment of spinal fractures is still highly controversed. The 


\begin{tabular}{|c|c|c|c|c|c|}
\hline & \multicolumn{5}{|c|}{ Pelvic incidence } \\
\hline & & $\begin{array}{c}\text { Low }<50^{\circ} \\
\mathrm{N}=29\end{array}$ & $\begin{array}{c}H \text { High } \geq 50^{\circ} \\
N=51\end{array}$ & $\begin{array}{l}\text { Overall } \\
(n=80)\end{array}$ & $P($ Khi 2) \\
\hline Level & $\begin{array}{l}\text { T10 } \\
\text { T12 } \\
\text { L4 } \\
\text { L1 } \\
\text { L2 } \\
\text { L3 }\end{array}$ & $\begin{array}{l}1 \\
6 \\
3 \\
5 \\
8 \\
6\end{array}$ & $\begin{array}{c}2 \\
6 \\
12 \\
20 \\
5 \\
6\end{array}$ & $\begin{array}{c}3 \\
12 \\
15 \\
25 \\
13 \\
12\end{array}$ & $P=0.071$ \\
\hline Denis & $\begin{array}{c}\text { BURST } \\
\text { SEAT-BELT } \\
\text { DISLOCATION }\end{array}$ & $\begin{array}{c}21 \\
5 \\
3\end{array}$ & $\begin{array}{c}29 \\
13 \\
9\end{array}$ & $\begin{array}{l}50 \\
18 \\
12\end{array}$ & $P=0.381$ \\
\hline Franckel & $\begin{array}{l}\text { A } \\
\text { B } \\
\text { C } \\
\text { D } \\
\text { E }\end{array}$ & $\begin{array}{c}5 \\
1 \\
1 \\
5 \\
17\end{array}$ & $\begin{array}{c}4 \\
2 \\
4 \\
4 \\
37\end{array}$ & $\begin{array}{c}9 \\
3 \\
5 \\
9 \\
54\end{array}$ & $P=0,404$ \\
\hline
\end{tabular}

Table 5: Correlation between pelvic incidence and vertebral Level, type, neurological status

\begin{tabular}{|c|c|c|c|c|c|c|c|}
\hline & \multicolumn{6}{|c|}{ Pelvic Incidence } & \multirow{3}{*}{$\mathrm{P}(\mathrm{KHI} 2)$} \\
\hline & \multicolumn{2}{|c|}{ Low $<50^{\circ}$} & \multicolumn{2}{|c|}{ High $\geq 50^{\circ}$} & \multicolumn{2}{|c|}{ Overall } & \\
\hline & $\mathrm{n}$ & $\%$ & $\mathrm{n}$ & $\%$ & $\mathrm{n}$ & $\%$ & \\
\hline overcorrection & 5 & 17.2 & 22 & 43.1 & 27 & 33.8 & $P<0.001$ \\
\hline $\begin{array}{l}\text { with normal } \\
\text { Correction }\end{array}$ & 4 & 13.8 & 18 & 35.3 & 22 & 27.5 & $P<0.001$ \\
\hline undercorrection & 20 & 69.0 & 11 & 35.5 & 31 & 21.6 & $P<0.001$ \\
\hline
\end{tabular}

Table 6: Correlation between pelvic incidence and correction of vertebral deformity

new techniques (screw, hooks, rod) improve the correction quality of the deformity of the kyphosis. If the vertebral deformity gives an idea about the importance of traumatism, the real regional deformity remains mal defined with or without the correlation with the injury level. In our opinion, this correlation depends on the shape of backs. Pelvic incidence is the only parameter calculated in injured patients. Relationships between this angle and the orientation of the sacrum, the sacral slope, and the characteristics of the lumbar lordosis were evident. For backs with high incidence (harmony curvature), the kyphosis deformity is meaningless if it is not correlated to the injury level. However, for backs with low incidence (long thoraco kyphosis or flat), this correlation is not obligatory. According to our study, pelvic incidence is not correlated to the traumatic deformity but it is proportional to the correction and loss. Therefore, the shape of back (pelvic incidence) appears fundamental in the choice of the number of vertebrae to fix above and below the fracture.

\section{References}

1. Steib JP, Aoui M, Mitulescu A, Bogorin I, Chiffolot X, et al. (2006) Thoracolumbar fractures surgically treated by "in situ contouring". Eur Spine J 15: 1823-1832.

2. Steib JP, Charles YP, Aoui M (2010) In situ contouring technique in the treatment of thoracolumbar fractures. Eur Spine J 19 Suppl 1: S66-68.

3. Roy-Camille R, Saillant G, Mazel C (1986) Internal fixation of the lumbar spine with pedicle screw plating. Clin Orthop Relat Res 7-17.

4. Yerby SA, Ehteshami JR, McLain RF (1997) Offset laminar hooks decrease bending moments of pedicle screws during in situ contouring. Spine (Phila Pa 1976) 22: 376-381

5. Briem D, Linhart W, Lehmann W, Bullinger M, Schoder V, et al. (2003) [Investigation of the health-related quality of life after a dorso ventral stabilization of the thoracolumbar junction]. Unfallchirurg 106: 625-632.

6. Katonis PG, Kontakis GM, Loupasis GA, Aligizakis AC, Christoforakis $\mathrm{JI}$, et al (1999) Treatment of unstable thoracolumbar and lumbar spine injuries using Cotrel-Dubousset instrumentation. Spine (Phila Pa 1976) 24: 2352-2357.

7. Knop C, Fabian HF, Bastian L, Blauth M (2001) Late results of thoracolumbar fractures after posterior instrumentation and transpedicular bone grafting. Spine (Phila Pa 1976) 26: 88-99.
8. Tropiano P, Huang RC, Louis CA, Poitout DG, Louis RP (2003) Functional and radiographic outcome of thoracolumbar and lumbar burst fractures managed by closed orthopaedic reduction and casting. Spine (Phila Pa 1976) 28: 2459-2465.

9. Burnham RS, Warren SA, Saboe LA, Davis LA, Russell GG, et al. (1996) Factors predicting employment 1 year after traumatic spine fracture. Spine (Phila Pa 1976) 21: 1066-1071.

10. Isomi T, Panjabi MM, Kato Y, Wang JL (2000) Radiographic parameters for evaluating the neurological spaces in experimental thoracolumbar burst fractures. J Spinal Disord 13: 404-411.

11. Kuklo TR, Polly DW, Owens BD, Zeidman SM, Chang AS, et al. (2001) Measurement of thoracic and lumbar fracture kyphosis: evaluation of intraobserver, interobserver, and technique variability. Spine (Phila Pa 1976) 26: 61-65.

12. Alvine GF, Swain JM, Asher MA, Burton DC (2004) Treatment of thoracolumba burst fractures with variable screw placement or Isola instrumentation and arthrodesis: case series and literature review. J Spinal Disord Tech 17: 251-264.

13. Benson DR, Burkus JK, Montesano PX, Sutherland TB, McLain RF (1992) Unstable thoracolumbar and lumbar burst fractures treated with the $\mathrm{AO}$ fixateur interne. J Spinal Disord 5: 335-343.

14. Korovessis P, Baikousis A, Koureas G, Zacharatos S (2004) Correlative analysis of the results of surgical treatment of thoracolumbar injuries with long Texas Scottish rite hospital construct: is the use of pedicle screws versus hooks advantageous in the lumbar spine? J Spinal Disord Tech 17: 195-205.

15. Leferink VJ, Nijboer JM, Zimmerman KW, Veldhuis EF, ten Vergert EM, et al (2003) Burst fractures of the thoracolumbar spine: changes of the spinal canal during operative treatment and follow-up. Eur Spine J 12: 255-260.

16. Wood KB, Bohn D, Mehbod A (2005) Anterior versus posterior treatment of stable thoracolumbar burst fractures without neurologic deficit: a prospective randomized study. J Spinal Disord Tech 18 Suppl: S15-23.

17. Legaye J, Duval-Beaupère G, Hecquet J, Marty C (1998) Pelvic incidence: a fundamental pelvic parameter for three-dimensional regulation of spinal sagittal curves. Eur Spine J 7: 99-103.

18. Duval-Beaupère G, Schmidt C, Cosson P (1992) A Barycentremetric study of the sagittal shape of spine and pelvis: the conditions required for an economic standing position. Ann Biomed Eng 20: 451-462.

19. Roussouly P, Labelle H, Rouissi J, Bodin A (2013) Pre- and post-operative sagittal balance in idiopathic scoliosis: a comparison over the ages of two cohorts of 132 adolescents and 52 adults. Eur Spine J 22 Suppl 2: S203-215.

20. Barrey C, Roussouly P, Perrin G, Le Huec JC (2011) Sagittal balance disorders in severe degenerative spine. Can we identify the compensatory mechanisms? Eur Spine J 20 Suppl 5: 626-633.

21. Charles YP, Bouchaïb J, Walter A, Schuller S, Sauleau EA, et al. (2012) Sagittal balance correction of idiopathic scoliosis using the in situ contouring technique. Eur Spine J 21: 1950-1956.

22. Jackson RP (1996) Lumbar burst fractures: fixation with pedicle instrumentation and reduction by adjustable countoured translating axes. The text book of spinal surgery, Chap. 2. Lippincott, Philadelphia

23. Argenson C, Puch J-M, de Peretti F, Perraud M, Cambas PM (1993) Le remodelage du canal verte'bral apre's traitement des fractures du rachis thoracolombaire. Rev Chir Orthop 79(Suppl 1):120.

24. Denis $F(1983)$ The three column spine and its significance in the classification of acute thoracolumbar spinal injuries. Spine (Phila Pa 1976) 8: 817-831.

25. Farcy JP, Weidenbaum M, Glassman SD (1990) Sagittal index in management of thoracolumbar burst fractures. Spine (Phila Pa 1976) 15: 958-965.

26. Roussouly P, Pinheiro-Franco JL (2011) Biomechanical analysis of the spinopelvic organization and adaptation in pathology. Eur Spine $\mathrm{J} 20$ Suppl 5: 609-618.

27. Argenson C, Farcy J-P, Floman Y (1993) Thoracolumbar spine fractures. Raven Press, New York.

28. de Peretti F. Cambas PM, Puch JM, Nasr ZG, Lovet J, et al. (1994) [Modular construction (2 HS-1 SH), using Cotrel-Dubousset's universal instrumentation for comminuted fractures of the thoracolumbar junction. Comparison with various other constructions]. Rev Chir Orthop Reparatrice Appar Mot 80: 205-216.

29. Bastian L. Lange U, Knop C, Tusch G, Blauth M (2001) Evaluation of the mobility of adjacent segments after posterior thoracolumbar fixation: a biomechanical study. Eur Spine J 10: 295-300. 
Citation: Aoui M, Trigui M, Naceur A, Abid A, Trigui N, et al. (2015) Influence of the Shape of Back on the Thoraco-lumbar Fractures. J Spine 4: 209. doi:10.4172/21657939.1000209

30. Fairbank JC, Couper J, Davies JB, O'Brien JP (1980) The Oswestry low back pain disability questionnaire. Physiotherapy 66: 271-273.

31. McLain RF (2004) Functional outcomes after surgery for spinal fractures: return to work and activity. Spine (Phila Pa 1976) 29: 470-477.

32. Mumford J, Weinstein JN, Spratt KF, Goel VK (1993) Thoracolumbar burst fractures. The clinical efficacy and outcome of nonoperative management. Spine (Phila Pa 1976) 18: 955-970.
33. McLain RF, Benson DR (1999) Urgent surgical stabilization of spinal fractures in polytrauma patients. Spine (Phila Pa 1976) 24: 1646-1654.

34. Vaccaro AR, Silber JS (2001) Post-traumatic spinal deformity. Spine (Phila Pa 1976) 26: S111-118.

35. Stagnara P, De Mauroy JC, Dran G, Gonon GP, Costanzo G, et al. (1982) Reciprocal angulation of vertebral bodies in a sagittal plane: approach to references for the evaluation of kyphosis and lordosis. Spine (Phila Pa 1976) 7: 335-342. 